\title{
Technological Aspects of Highly Selective Synthesis of Allyloxyalcohols-New, Greener, Productive Methods
}

\author{
Magdalena Urbala (D) \\ Department of Chemical Organic Technology and Polymeric Materials, Faculty of Chemical Technology and \\ Engineering, West Pomeranian University of Technology, 42 Piastów Avenue, 71-065 Szczecin, Poland; \\ mu@zut.edu.pl
}

check for updates

Citation: Urbala, M. Technological Aspects of Highly Selective Synthesis of Allyloxyalcohols-New, Greener, Productive Methods. Catalysts 2021, 11, 1559. https://doi.org/10.3390/ catal11121559

Received: 30 November 2021 Accepted: 17 December 2021 Published: 20 December 2021

Publisher's Note: MDPI stays neutral with regard to jurisdictional claims in published maps and institutional affiliations.

Copyright: (C) 2021 by the author. Licensee MDPI, Basel, Switzerland. This article is an open access article distributed under the terms and conditions of the Creative Commons Attribution (CC BY) license (https:// creativecommons.org/licenses/by/ $4.0 /)$.
Abstract: Allyl ethers bearing free hydroxyl groups of $\mathrm{CH}_{2}=\mathrm{CH}-\mathrm{CH}-\mathrm{O}-\mathrm{A}-\mathrm{OH}$ type (hydroxyalkyl allyl ethers, allyloxyalcohols) are valuable chemicals in many environmentally friendly industrial applications. The development of technologically attractive methods for their production is necessary. The two pathways (L-L PTC and non-catalytic solvent-free conditions) were optimized for the highly selective and yield synthesis of 4-allyloxybutan-1-ol. Improvements in the PTC method (50\% $\mathrm{NaOH}(\mathrm{aq})$, the equimolar ratio of $\mathrm{NaOH}$ to diol, cyclohexane as solvent) with a new highly selective and effective PT catalyst, i.e., $\mathrm{Me}(n-\mathrm{Oct})_{3} \mathrm{~N}^{+} \mathrm{Br}^{-}(0.3 \mathrm{~mol} \%)$, resulted in $88 \%$ yield and $98 \%$ selectivity of 4-allyloxybutan-1-ol with minimal formation of allyl chloride hydrolysis by-products $(<1 \%)$. In turn, application of non-catalytic solvent-free conditions and the change in the key substrate with an excess of diol and use of solid $\mathrm{NaOH}$ solely led to a mono-O-allylation product with an excellent yield of $99 \%$ in a relatively short reaction time $(3.5 \mathrm{~h})$, with trace amounts of by-products $(<0.1 \%)$. This sustainable method is perfectly suitable for the synthesis on a larger scale ( 3 moles of the key substrate) and for the full $O$-allylation process.

Keywords: allyl ethers; allyloxyalcohols; allylation; mono-O-allylation; phase transfer catalysis (PTC); Williamson ether synthesis

\section{Introduction}

Today, the multifunctional organic intermediates used in general organic synthesis as well as in industrial high functionality required applications are preferred. The relatively easily synthesized fine chemicals, which offers an interesting alternative for new routes to bio-based functional molecules, have a particular meaning. Allyl ethers and their functionalized derivatives are one of the most established compounds in modern organic chemistry, including the procedure of protection/deprotection of alcohols (especially important in carbohydrate chemistry), 1,3-hydrogen shift, oxidation, epoxidation, hydrosilylation, Claisen or 2,3-Wittig rearrangement, Diels-Alder reaction, asymmetric synthesis, electrochemical reduction, surface modifications and many others [1,2]. On the other hand, besides simple low-molecular-weight compounds such as diallyl ether or simple allyl alkyl ethers, polyallyl alkyl ethers with additional functional groups constitute one of the valuable chemicals in many industries. They are especially used in the free radical or cationic photocuring production of advanced hybrid polymer systems, mainly as monomers, crosslinkers, modifiers, or reactive diluents [3,4]. Due to the versatile and high functionality required applications, a substantial commercial importance have allyl alkyl ethers of diols or polyols, i.e., hydroxyalkyl allyl ethers or allyloxyalcohols, which contain highly reactive allyl and hydroxyl groups in one molecule. Wide ranging transformations of allyloxyalcohols open up pathways for one-step synthesis of large variety hybrid systems, fundamental for environmentally friendly industrial applications (Scheme 1). 


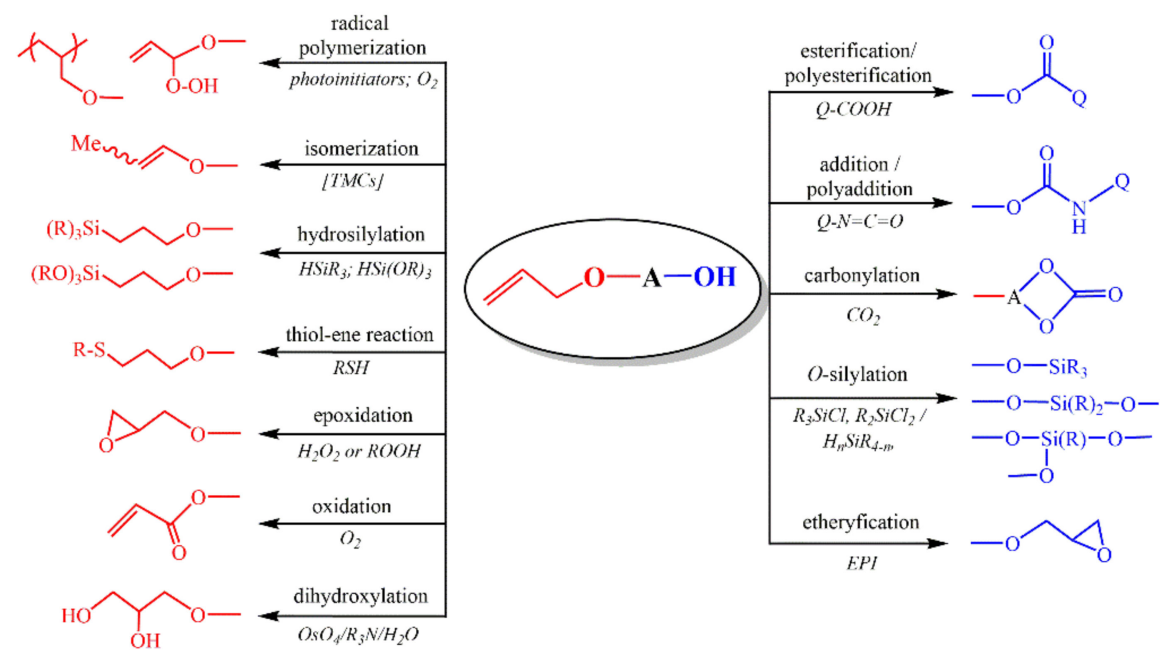

Scheme 1. Selected industrially important one-step transformations of allyloxyalcohols.

As can be seen on the left side of Scheme 1, first of all, the allyl ethers are well-known oxygen-sensitive valuable comonomers for the free radical $U V$-curing coatings industries in air-drying applications based on unsaturated resins [4-6]. Nowadays, the open-air free radical photocuring with using acrylate, unsaturated polyester resins (UPR) and others is the dominant technology for industrial green $U V$-production of polymeric layers (up to $95 \%)$, mainly due to the fast and versatile chemistry and the wide commercial availability of various suitable monomers and photoinitiators [7]. Moreover, the allyl ethers also play a role in non-hazardous reactive diluents and crosslinking agents in the polyesters systems, affecting both the cure rate and the good final properties of the polyester styrene-free products [8]. The allyl ether unit could serve as starting point to various other functional groups. Specifically, the well-known versatile isomerization of multi-functional allyl ether catalyzed by transition metal complexes, especially Ru bases, leads to 1-propenyl ether derivatives - the most reactive and desire monomers for the cationic photopolymerization [9-14]. The attractive and sustainable cationic formulations based on epoxy, oxetane, or vinyl and 1-propenyl resins cured by $U V$-onium-type photoinitiators consist only of ca. $5 \%$ of the radiation curing market and they are used in the case of challenging sensitive applications. Moreover, the carbon-carbon double bond of allyl ether molecule can undergo highly efficient fast reactions with silanes $\left(\mathrm{R}_{3} \mathrm{SiH}\right.$ type) or hydrosiloxanes $\left((\mathrm{RO})_{3} \mathrm{SiH}\right.$ type) and also thiols (RSH type), which has been used extensively inter alia for the functionalization of polymer materials or the synthesis of multifunctional $U V$-cured monomers [15-17]. Recently, the importance of the thiol-ene "click chemistry" with allyl ethers in the environmentally friendly polymer coatings, material science, dendrimers, surface modification, and biotechnology areas, is constantly increasing [18]. Additionally, big progress has been achieved in the field of the green oxidation processes of the double bond of allyl functionality, especially in the direct epoxidation towards glycidyl ethers or aerobic catalytic oxidation to acrylates $[19,20]$ with using the safe, easy to handle and cheap oxidants such as hydrogen peroxide $\left(\mathrm{H}_{2} \mathrm{O}_{2}\right)$ or oxygen $\left(\mathrm{O}_{2}\right)$ and without generating toxic by-products. The attractive pathway for the synthesis of fine and specialty chemicals such as alkyl glycerol monoethers (GMEs) is the well-known direct dihydroxylation of alkyl allyl ethers under oxidative conditions [21-23], including the high stereoselective synthesis of dihydroxyether derivatives [24].

On the other hand, the presence of hydroxyl group in the allyloxyalcohol molecule opens the way for easily synthetic pathways of the valuable allyl ether functionalized monomers/oligomers/polymers with a large variety of different reactive groups (Scheme 1, right side). First, the well-known simple esterification (condensation or polycondensation) reaction of various organic dicarboxylic acids/anhydrides typically phthalic, maleic, isophthalic, terephthalic, adipic, or succinic ones and fatty acids, creates the possibility of 
producing polymerizable multifunctional allyl ether carboxylate ester monomer hybrid systems, including hyperbranched polymers or unsaturated polyester resins (UPRs) [19-25]. The introduction of an allyloxy alkyl group from allyloxyalcohol instead of a simple allyl group from allyl alcohol gives the monomer molecules provides regulated length of their carbon chain, and, in consequence, changes the properties of resulted polymeric materials. Next, the hydroxyl end-group functionality gives the advantage of obtaining well-established urethanes/polyurethanes (PUs) [26]. In this area, due to the specific hydrophilic properties, the allyl ether functionalized diols-based on inexpensive and readily available carbohydrates as renewing resources-constitute an excellent approach to prepare novel biodegradable and biocompatible urethane materials for application in the biomedical field and other sectors such as foodstuff packaging. Additionally, this type of allyl sugar "green monomers" can be intermediates for the post-functionalization of polycarbonates by a thiol-ene "clik" coupling reaction $[27,28]$. Indeed, the reverse path can be used, namely thiol-ene coupling of mercaptanized biobased compounds with double bonds from the allyloxyalcohols, resulting in allyl ether-functionalized diols as renewable polyols for polyurethanes [29]. The other interesting class of sustainable materials are the allyloxy five- or six-membered cyclic carbonate, one-step-synthetized from allyl ether polyols derivatives (especially 1,2- or 1,3-diols type). They are intensively studied as a new and attractive industrial class of reactive monomers, e.g., for green synthesis of isocyanate-free polyhydroxyurethanes (PHU) or solid polymer electrolytes (SPEs) [30,31].Importantly, an accessible, cheap, and renewable resource of polyols, e.g., glycerine (and next their partial allylation products) and/or $\mathrm{CO}_{2}$ as ring-closing reagent, can be used and the reaction often proceeds under ambient pressure and temperature conditions [30-33]. Furthermore, the classical way of $O$-silylation allyloxyalcohols toward alkoxysilanes, silyl ethers, siloxanes, etc., relies mostly on the reaction with chlorosilanes in the presence of a base [34], or with 1,1,1,3,3,3-hexamethyldisilazane (HMDS) - more green but limited only to trimethylsilyl ether derivatives [35]. In recent years, the modern clean halogen-free alternative via the direct dehydrogenative coupling reaction of hydroxyl groups with hydrosilanes was developed with molecular hydrogen as the only by-product [36]. On the contrary, the chlorine methods using epichlorohydrine (ECH or EPI) as epoxy agents of alcohols dominates in the industrial production of highly reactive epoxy intermediates and epoxy resins [37]. Recently, bio-based ECH from glycerin (by-product of biodiesel production) has become commercially available. Although EPI is flammable and considered a hazardous chemical, it is still an important building block in the chemical industry with a global production exceeding 2 million tonnes per year and growing at a CAGR of $4.6 \%$ to 2027 [37]. Again, allyloxyalcohols with a linker $\mathrm{A}$ in the molecule provide specific properties to the final epoxy compounds. For example, the well-defined poly(ethylene glycol) (PEG) backbone has a significant impact on excellent solubility in aqueous media, flexibility, non-toxicity, and biocompatibility [38].

Undoubtedly, the alkyl allyloxyalcohols are attractive and valuable compounds for many applications, however, only a few are commercially available in large-scale production, mainly:

- $\quad$ the monoallyl ethers of ethylene or propylene glycols or polyglycols, obtained via the alkoxylation of AA by ethylene oxide or propylene oxide; of course, this synthetic way solely leads to allyloxyalcohols but it is limited to only one type of them containing one allyl and one hydroxyl group in the molecule;

- the allyl ethers of partially substituted polyols such as neopentl glycol, glycerol, pentaerythritol, and trimethylolpropane, easily produced by the partial etherification of polyols with allylating agents ( $\mathrm{O}$-allylation reaction), this is much more universal and more commonly used in the case of multifunctional, smart, and environmentally friendly bio-renewable allyl ethers (Scheme 2). 


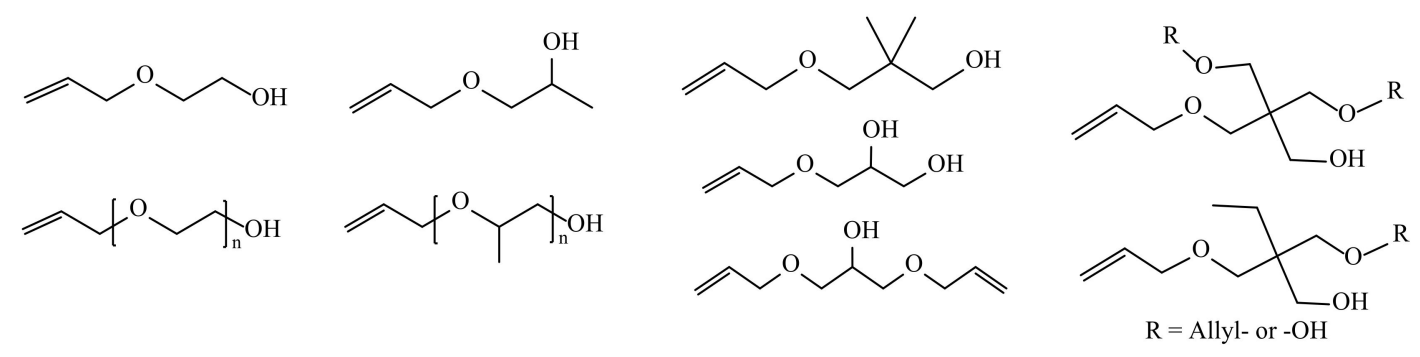

Scheme 2. The large-scale available allyloxyalcohols.

It should be noted, however, that most allyloxyalcohols from polyols are obtained as a mixture of all possible allylation products with the technical purity of $70-90 \%$ of the dominant product. It is due to their non-selective synthesis and the difficulties in the highly efficient fractional distillation or rectification. Products of this type could be used as the components of compositions for polymerizations, but not as the substrates for the highly selective synthesis of the multifunctional compounds with well-defined structures, additionally catalyzed by extremely reactive catalysts requiring the highest quality reagents, e.g., transition metal complexes.

Therefore, it is highly desirable to develop an efficient method for the partial etherification of aliphatic polyols with the maximum selectivity to allyloxyalcohols. Generally, simple allyloxyalcohols are produced on a technical scale by Williamson-type synthesis from alcohol with allyl halides (usually allyl chloride) in the presence of a base (inter alia to neutralize the acid produced) in a suitable solvent medium. The modification of this method includes phase transfer catalysts (PTC), thus reactions are conducted in a two-phase system under mild and safe conditions often with high yield, and selectivity towards major products [3]. Additionally, a variety of green, halogen-free, and high-yielding methods have been recently developed for the synthesis of allyl ethers with allyl alcohol, allylic acetates, or allylic carbonates as allylating agents. Although the reactions proceed without the formation of waste halides, they are practically limited to phenols or, a much lesser extent, simple alcohols (owing to their poor nucleophilicity) and, importantly, require the use of very expensive and often non-recyclable homogeneous catalysts such as $\mathrm{Pd}, \mathrm{Ru}$ or Ir complexes [39-42]. However, it should be pointed out that only one work of the mono$\mathrm{O}$-allylation of polyols catalyzed by [Pd]/Lewis acid systems has appeared, but only for saccharides, for which the high selectivity of the reaction was achieved due to different, by their nature, nucleophilic properties of the hydroxyl groups [42]. For the development of a more practical etherification way with a reusable catalyst under heterogeneous conditions, the highly dispersed $\mathrm{MoO}_{3}$ catalyst supported on $\mathrm{TiO}_{2}$ was proposed for the dehydrative allylation of allyl alcohol with simple aliphatic alcohols under solvent-free conditions [43]. In this sustainable manner case with water as the sole by-product, only simple allyl ether can be obtained with a yield of up to a $91 \%$.

Over the years, in our laboratory we have concentrated on the modern, clean, and practical attractive strategies of the synthesis of the high purified multifunctional allyl ether substrates under PTC conditions, [34,44], their [Ru]-catalyzed transformations into 1-propenyl ether derivatives [10-14] and, finally, the application of obtained monomers in the $U V$-curing polymeric systems [45-47] (Scheme 3).

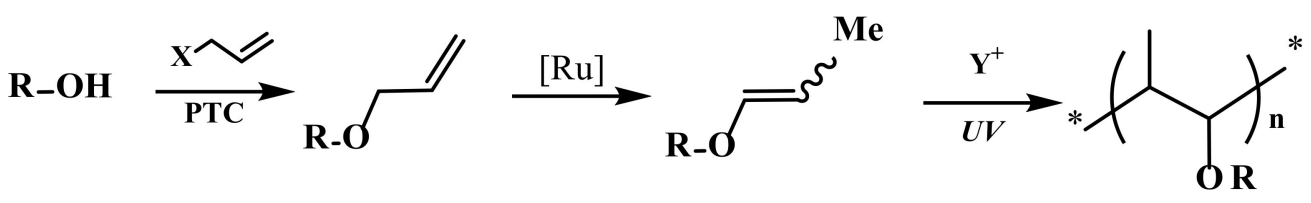

Scheme 3. The strategy of the synthesis and application of allyl ether monomers.

Recently, we have demonstrated the extreme reactivity of 4-allyloxybutan-1-ol with the homogeneous ruthenium complexes and in consequence the highly productive synthesis of 
1-propenyloxyalcohol monomer [14]. Therefore, for the successful realization of our practical strategy (Scheme 3), in this work, we focused our attention on the technologically attractive high selective and easily scalable method of the high pure 4-allyloxybutan-1-ol production (Scheme 4). It is important that, in contrary to 2-allyloxyethanol, 4-allyloxybutan-1-ol is not produced on the industrial scale.

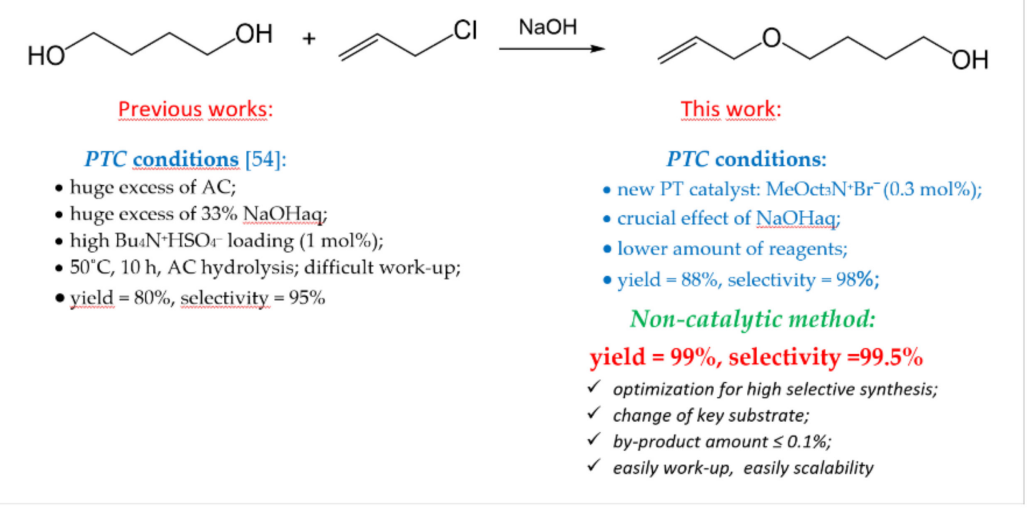

Scheme 4. Concept of high productive synthesis of allyloxyalcohols.

The partial $O$-allylation of butane-1,4-diol by allyl chloride was chosen for this purpose. Butane-1,4-diol (BDO) is a well-known bulk chemical, widely used as a key intermediate in many industries (fine chemicals, polymers, pharmaceuticals, solvents) with a growing global market of ca. 4.3 million tons per year and progressing at a CAGR of ca. $7.7 \%$ to 2026. BDO is traditionally produced from petrochemical-based sources, but recently, bio-based butanediol at an industrial scale from bio-succinic acid or from dextrose has been manufactured [48,49]. Similarly, the bulk allyl chloride (AC) is the cheapest and the most commercially available allylating agent with a worldwide production volume above 800,000 tons per year in 1997 [3]. Although AC is toxic and flammable, it is very reactive and is used widely as a crucial chemical component in many industries and applications (EPI, resins, polymers, plastic materials, urethanes, adhesives, flame retardants, allylic compounds, pesticides, pharmaceuticals, detergents, water treatment chemicals, and various other products) [3]. Synthetic 4-allyloxybutan-1-ol pathways described in the literature are based on the reaction of BDO with the expensive allyl bromide with $\mathrm{NaH}$ under anhydrous conditions mainly on the laboratory scale or on the preparative scale under PTC conditions [50,51]. In most reported cases, no yield and selectivity values are given. To our best knowledge, for allyl chloride, the best yield results (80\%) and selectivity (95\%) of 4-allyloxybutan-1-ol were developed by us previously [44]. The process was run in the biphasic liquid-liquid system (L-L PTC) with an excess of allyl chloride (the molar ratio of $\mathrm{AC}: \mathrm{BDO}=3.5$ ) and $\mathrm{NaOH}$ (the molar ratio of $\mathrm{NaOH}: \mathrm{BDO}=2.5$ ) in an aqueous solution $(35 \%)$ using tetra- $n$-butylammonium hydrogen sulfate $\left(\mathrm{Bu}_{4} \mathrm{~N}^{+} \mathrm{HSO}_{4}{ }^{-}\right)$as the PT-catalyst $(1 \mathrm{~mol} \%)$ in toluene solution (the volume ratio of $\mathrm{AC}$ :toluene $=1.5$ ) at a temperature of $50{ }^{\circ} \mathrm{C}$ within $10 \mathrm{~h}$. Unfortunately, during the prolongated heating time, the formation of the products of allyl chloride hydrolysis such as allyl alcohol and allyl ether with a yield of up to a $18 \%$ was observed [44]. Moreover, the multiple extractions of the monoallylation product, long duration of the aqueous and organic phases separation, and the use of large amounts of drying agents for the organic layer due to the relatively high solubility of toluene in water $\left(52.6 \mathrm{mg} / 100 \mathrm{~g} \mathrm{H}_{2} \mathrm{O}\right.$ at $\left.25^{\circ} \mathrm{C}\right)$ were also disadvantageous.

Therefore, according to all of the above and in the continuation of our study, in this work, the highly selective synthesis of 4-allyloxybutan-1-ol using BDO and AC as reagents was technologically optimized under the L-L PTC pathway and under non-catalytic solventfree conditions. The effect of the reaction conditions such as the excess of a key substrate, the amount of base $(\mathrm{NaOH})$ and its form (aqueous solution or solid), the type and the concentration of PT catalyst, the type of solvent on the possible high reaction selectivity to 4-allyloxybutan-1-ol within reasonable reaction times, and excluding AC hydrolysis 
were conducted. Additionally, the problems of the efficient separation and purification of the main product from the reaction mixture, process safety, and easy scalability were also considered.

\section{Results and Discussion}

The reaction of butane-1,4-diol (BDO) with allyl chloride (AC) via the Williamson-type protocol in the presence of strong base $\mathrm{NaOH}$ runs mainly toward the monoallylation and diallylation products, i.e., 4-allyloxybutan-1-ol (ABO) and 1,4-bisallyloxybutane. The major organic by-products formed during the base hydrolysis of allyl chloride are allyl alcohol and diallyl ether. Additionally, the generation of inorganic products such as $\mathrm{NaCl}$ and $\mathrm{H}_{2} \mathrm{O}$ are observed (Scheme 5) [44].

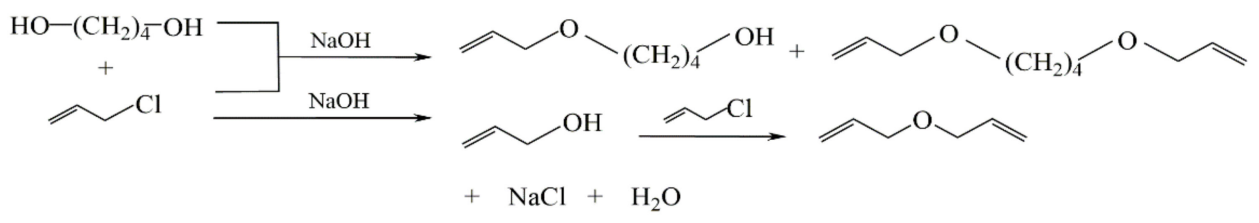

Scheme 5. The allylation of butane-1,4-diol by allyl chloride in the presence of $\mathrm{NaOH}(\mathrm{aq})$.

Generally, the highly selective mono-O-allylation reaction of symmetric BDO is difficult to perform due to the presence of two primary, terminal, and chemically equivalent hydroxyl groups in the diol molecule. Therefore, the experimental investigation of the technological usability of the high effective 4-allyloxybutan-1-ol synthesis involves the careful and extensive optimization of many process factors such as base, solvent, the order of addition of reagents, the reaction time, and temperature. In this work, the two approaches were explored. First, we modified the L-L PTC method, developed by us previously [44], and in the second method, we applied no-catalytic and solvent-free conditions.

\subsection{Mono-O-Allylation Reaction under PTC Conditions}

It is well known that phase transfer catalysis is the most universal, efficient, and environmentally friendly methodology to perform organic reactions between two reagents located in different immiscible phases, usually via transferring of an organic anionic species from an aqueous or solid phase or interface to an organic phase. Due to its numerous and important advantages such as high yields, non-dry mild reaction conditions, reproducibility and reliability, enhanced safety by better control of temperature, the PTC method is applied successfully in a wide range of organic reactions in industry, especially when active and cheap tetraalkylammonium (TAA) salt is used as a PT catalyst $[52,53]$. Therefore, according to the relatively good results of yield ( $80 \%)$ and selectivity $(95 \%)$ of 4 -allyloxybutan-1-ol obtained previously [44], we first continued the optimization of process parameters using $\mathrm{Bu}_{4} \mathrm{~N}^{+} \mathrm{HSO}_{4}^{-}$as the L-L PT-catalyst for better confirming the technological usefulness of this methodology. The priority in the process modification was to increase the selectivity value to at least $98 \%$ with a reasonable yield of the desired allyloxyalcohol product and to prevent hydrolysis of $\mathrm{AC}$, as well as to simplify work-up and minimize waste.

For these purposes, the effect of concentrated aqueous solutions of $\mathrm{NaOH}$ on the O-allylation reaction course was first studied-with respect to the other crucial reaction parameters. Generally, although the mechanisms of substitution reactions in the PTC/NaOH system are more complicated, the role of $\mathrm{NaOH}(\mathrm{aq})$ in L-L PTC is relatively well known [54-56]. In short, the $\mathrm{NaOH}(\mathrm{aq})$, located in the inorganic phase, is essential to the deprotonation initial step of appropriate organic substrates for the generation of organic anions (the acid-base equilibrium) in the interface between the immiscible phases and their subsequent ion exchange with TAA salt. The resulting lipophilic ion pairs TAA cation/organic anion are then transferred into the organic phase, where the main reaction takes place. Therefore, deprotonation is a key step of the process and its efficiency is a function of organic compounds acidity. Butan-1,4-diol is a relatively weak organic acid 
( $\mathrm{pKa}=14.5$ at $25^{\circ} \mathrm{C}$ [57]), and, considering that the pKa value of water equals ca. 15.7, it can undergo reaction with $\mathrm{NaOH}(\mathrm{aq})$ into sodium alkoxides (butanodiolate ions). Moreover, it is well known that sodium alkoxides generated in situ are much more reactive with alkyl halogens in the nucleophilic substitution of $\mathrm{SN}_{2}$ than the primary alkyl hydroxyl groups. It should be also stressed that under $\mathrm{PTC} / \mathrm{NaOH}$ conditions both processes, e.g., deprotonation and substitution could be accelerated by the TAA catalyst [54].

In these experiments, $\mathrm{BDO}$ was the key substrate. The $\mathrm{O}$-allylation reaction was carried out by the one-pot and one- or two-step methodology at a temperature of $50{ }^{\circ} \mathrm{C}$ with an excess of $\mathrm{AC}$ (the molar ratio of $\mathrm{AC}: \mathrm{BDO}=3.5$ ) in the in toluene or cyclohexane (the volume excess to $\mathrm{AC}=1.5$ ) in the presence of $0.1 \mathrm{~mol} \%$ or $1 \mathrm{~mol} \%$ of $\mathrm{Bu}_{4} \mathrm{~N}^{+} \mathrm{HSO}_{4}{ }^{-}$. In the one-step approach, all essential reactants were sequentially introduced into the reactor. In the two-step procedure, during the first deprotonation step, $\mathrm{BDO}$ reacted with $35 \%$ or $50 \%$ of $\mathrm{NaOH}(\mathrm{aq})$ at a temperature of $50{ }^{\circ} \mathrm{C}$ or $90^{\circ} \mathrm{C}$ for up to $30 \mathrm{~min}$, then (after cooling if necessary), the PT catalyst and the CA mixture in a solvent were added and the allylation reaction (second step) proceeded for up to $10 \mathrm{~h}$. The reaction progress was monitored in time by the GC internal standard method and the practically significant results of the selectivity and yield of the 4-allyloxybutan-1-ol $\left(\mathrm{S}_{\mathrm{ABO}}, \mathrm{Y}_{\mathrm{ABO}}\right)$ together with the percentage of AC hydrolysis products, i.e., allyl alcohol $\left(\mathrm{Y}_{\mathrm{AA}}\right)$ and diallyl ether $\left(\mathrm{Y}_{\mathrm{AE}}\right)$ are presented in Table 1 . The results of the previously optimized PTC conditions [54] were also added for comparison (entry 1).

Table 1. The mono-O-allylation of butane-1,4-diol by allyl chloride in the presence of $\mathrm{NaO}(\mathrm{aq})$ catalyzed by $\mathrm{Bu}_{4} \mathrm{~N}^{+} \mathrm{HSO}_{4}{ }^{-}$ (1) as PT catalyst: the effect of $\mathrm{NaOH}(\mathrm{aq})^{1}$.

\begin{tabular}{|c|c|c|c|c|c|c|c|c|}
\hline Entry & $1(\mathrm{~mol} \%)$ & $\begin{array}{l}\text { NaOH:BDO } \\
\text { Molar Ratio }\end{array}$ & $\begin{array}{l}\mathrm{NaOH}(\mathrm{aq}) \\
\text { Conc. }(\%)\end{array}$ & $\begin{array}{c}\text { I Step } \\
\text { Time }(\mathrm{min}) / \mathrm{t}\left({ }^{\circ} \mathrm{C}\right)\end{array}$ & $\begin{array}{c}\text { II Step } \\
\text { Time } \\
\text { (h) } / 50{ }^{\circ} \mathrm{C} / \mathrm{So}\end{array}$ & $\mathrm{S}_{\mathrm{ABO}}(\%)$ & $\mathrm{Y}_{\mathrm{ABO}}(\%)$ & $\mathrm{Y}_{\mathrm{AA}} / \mathrm{Y}_{\mathrm{AE}}(\%)$ \\
\hline $\begin{array}{l}1 \\
2\end{array}$ & 1 & 2.5 & 35 & $\begin{array}{l}30 / 90 \\
30 / 50\end{array}$ & $10 / \mathrm{T}$ & $\begin{array}{l}95 \\
97\end{array}$ & $\begin{array}{l}80 \\
68\end{array}$ & $\begin{array}{l}3 / 15 \\
8 / 5\end{array}$ \\
\hline $\begin{array}{l}3 \\
4 \\
\end{array}$ & 1 & 0.6 & 50 & $\begin{array}{l}30 / 90 \\
30 / 50\end{array}$ & $\begin{array}{l}10 / \mathrm{T} \\
10 / \mathrm{T}\end{array}$ & $\begin{array}{l}97 \\
98\end{array}$ & $\begin{array}{l}58 \\
51\end{array}$ & $\begin{array}{c}2 / 2 \\
1.5 / 1\end{array}$ \\
\hline $\begin{array}{l}5 \\
6 \\
7 \\
8 \\
9\end{array}$ & 1 & 1 & 50 & $\begin{array}{c}30 / 90 \\
30 / 50 \\
30 / 50 \\
15 / 50 \\
-\end{array}$ & $\begin{array}{l}6 / \mathrm{T} \\
6 / \mathrm{T} \\
8 / \mathrm{T} \\
8 / \mathrm{T} \\
8 / \mathrm{T}\end{array}$ & $\begin{array}{l}84 \\
96 \\
86 \\
88 \\
92\end{array}$ & $\begin{array}{l}81 \\
72 \\
87 \\
84 \\
63\end{array}$ & $\begin{array}{c}2 / 2 \\
1.5 / 1 \\
2 / 1.3 \\
1 / 1 \\
2 / 1\end{array}$ \\
\hline $\begin{array}{l}10 \\
11 \\
12 \\
13 \\
14 \\
15\end{array}$ & 0.1 & 1 & 50 & $15 / 50$ & $\begin{array}{c}6 / \mathrm{T} \\
8 / \mathrm{T} \\
10 / \mathrm{T} \\
6 / \mathrm{C} \\
8 / \mathrm{C} \\
10 / \mathrm{C}\end{array}$ & $\begin{array}{c}98 \\
96 \\
94 \\
\sim 98 \\
95 \\
95\end{array}$ & $\begin{array}{l}54 \\
61 \\
65 \\
57 \\
66 \\
69\end{array}$ & $\begin{array}{c}2 / 1 \\
\sim 2 / 1.5 \\
2.5 / 2 \\
\text { traces } \\
1 / 1 \\
1.2 / 1\end{array}$ \\
\hline $\begin{array}{c}16 \\
17 \\
18^{2} \\
19^{3}\end{array}$ & - & 1 & 50 & $15 / 50$ & $\begin{array}{l}8 / C \\
48 / C \\
6 / C \\
6 / C\end{array}$ & $\begin{array}{c}100 \\
99 \\
97 \\
95\end{array}$ & $\begin{array}{l}37 \\
88 \\
47 \\
59\end{array}$ & $\begin{array}{c}1.5 / 1 \\
4 / 3 \\
1 / 1 \\
\text { traces }\end{array}$ \\
\hline
\end{tabular}

${ }^{1}$ The reaction conditions: 0.3 mole scale of $\mathrm{BDO}$, the molar ratio of $\mathrm{AC}: \mathrm{BDO}=3.5$, the volume ratio of solvent: $\mathrm{AC}=1.5$ (So-solvent, $\mathrm{T}$-toluene, $\mathrm{CH}-$ cyclohexane), mechanical paddle stirrer. ${ }^{2}$ The $\mathrm{NaCl}$ was added in the molar ratio of $\mathrm{NaCl}$ : $\mathrm{BDO}=0.5 .{ }^{3} \mathrm{The} \mathrm{NaCl}$ was added in the molar ratio of $\mathrm{NaCl}: \mathrm{BDO}=2$.

In general, we found that the mono- and di-O-allylation of $\mathrm{BDO}$ with $\mathrm{AC}$ in the presence of $\mathrm{NaOH}(\mathrm{aq})$ are the consecutive reactions (Figure 1), therefore, it is possible to obtain the desired mono-O-allylation product with an assumed selectivity value of at least $98 \%$. The spectacular results of $88 \%$ yield of practically only 4 -allyloxybutan-1-ol were obtained when the reaction was run without catalyst but within the unfavorable long reaction time of $48 \mathrm{~h}$ (Figure 1a, entry 17 in Table 1). On the other hand, using the 
$\mathrm{Bu}_{4} \mathrm{~N}^{+} \mathrm{HSO}_{4}{ }^{-}$as PT catalysts significantly enhanced the reaction, and the high yield values of $\mathrm{ABO}$ are noted in time, but, simultaneously, the di-O-allylation by-product is formed (Figure 2, entries 1-15).

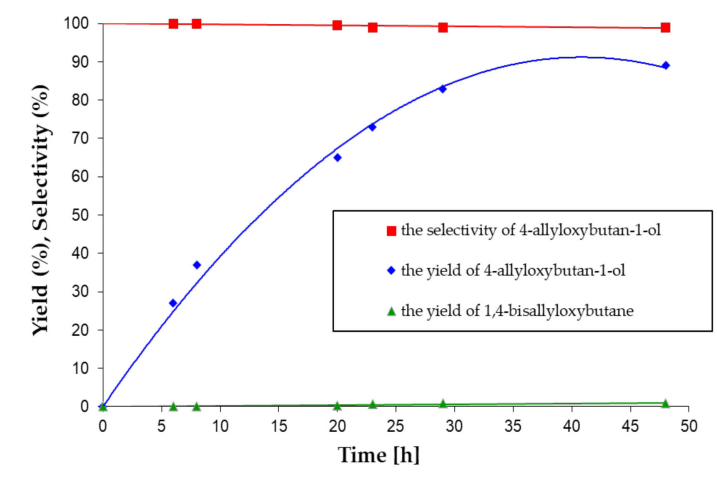

(a)

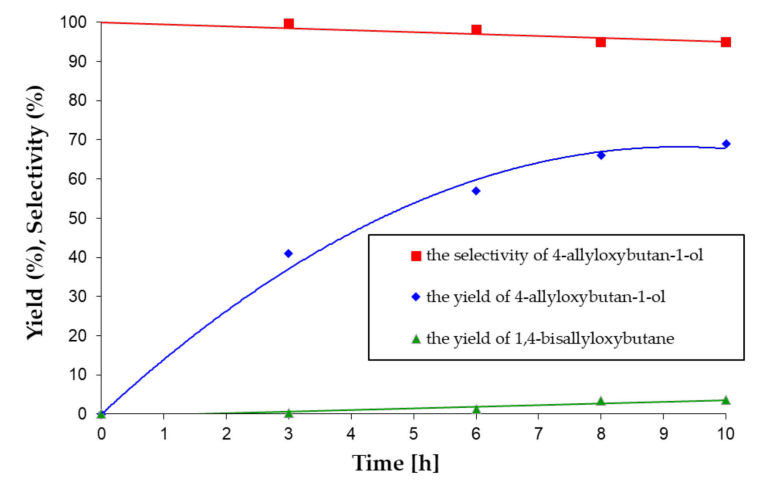

(b)

Figure 1. The time course reaction profile of $O$-allylation of butane-1,4-diol by allyl chloride in the presence of $50 \% \mathrm{NaOH}(\mathrm{aq})$ under (a) non-catalyzed or (b) catalyzed by $0.1 \mathrm{~mol} \%$ of $\mathrm{Bu}_{4} \mathrm{~N}^{+} \mathrm{HSO}_{4}{ }^{-}$conditions (the reaction conditions: see Table 1 entries 16-17 and 13-15, respectively).

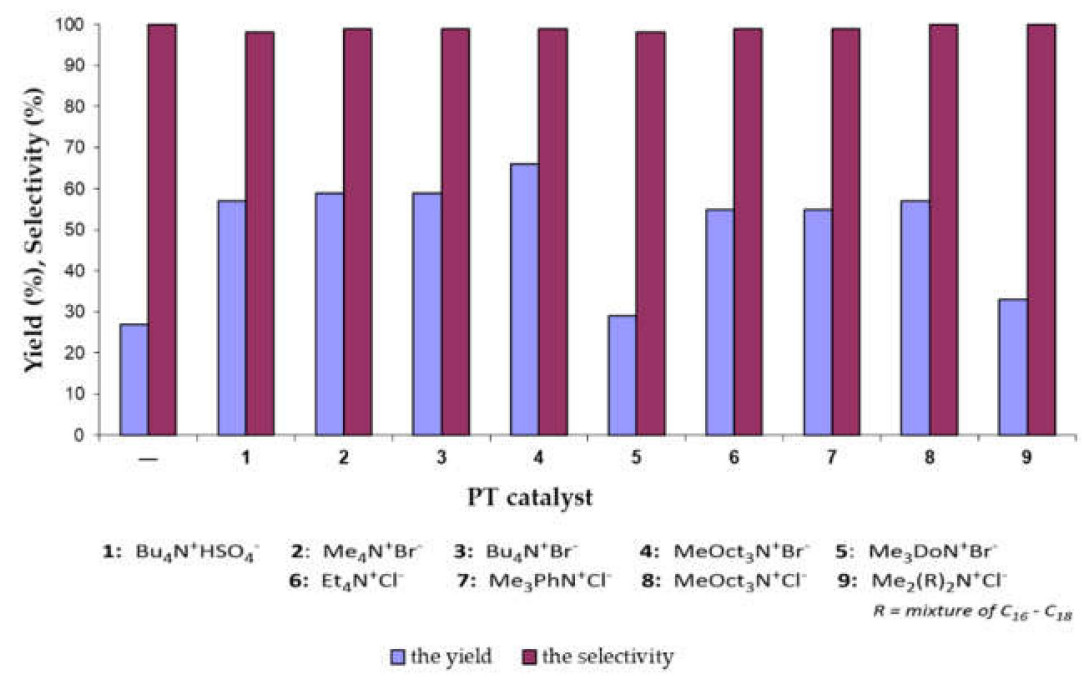

Figure 2. The catalytic activity of tetraalkylammonium salts $(0.1 \mathrm{~mol} \%)$ in the mono-O-allylation of butane-1,4-diol by allyl chloride toward 4-allyloxybutan-1-ol in the presence of $50 \% \mathrm{NaOH}(\mathrm{aq})$ (the reaction conditions: see Table 1 , entry 13 ).

For higher selectivity to allyloxyalcohol, the reaction conditions of the deprotonation of diol by $\mathrm{NaOH}(\mathrm{aq})$ were first optimized (entry 2). It should be pointed out that according to our knowledge, the influence of this crucial step on the process course is practically overlooked in the literature. There are two main ways of PTC methodology of the Williamson-type synthesis, namely via the one-step procedure [58] or two-step ones with conducting a separate deprotonation reaction at higher temperatures ca. $70-90{ }^{\circ} \mathrm{C}$ within a given time [44,59]. Our research indicates that in order to obtain reasonable overall reaction efficiency this step cannot be avoided (compare entry 9 with entries 7 and 8). Moreover, the lowering of temperature from 90 to $50^{\circ} \mathrm{C}$ gave visibly higher values of $\mathrm{ABO}$ selectivity, even by ca. $12 \%$, and relatively high yields of $\mathrm{ABO}$ (compare entries 1 and 2, 3 and 4, 5, and 6, respectively). Two-fold shortening of the deprotonation reaction time from $30 \mathrm{~min}$ to $15 \mathrm{~min}$ did not significantly affect the expected final results (entries 7 and 8).

A subsequent crucial aspect to the enhancement of the technological PTC method usability is the determination of the amount and the concentration of $\mathrm{NaOH}(\mathrm{aq})$. According 
to published data on the advisability of using a higher concentration of alkali solution $(40-50 \%)$, the $50 \% \mathrm{NaOH}(\mathrm{aq})$ was successfully applied. The higher concentration of alkali solutions limits AC hydrolysis [60] and allows for the extraction of alcoholate anion into the organic phase as $\mathrm{TAA}^{+} \mathrm{OR}^{-}$due to the high hydrophilicity of $\mathrm{OH}^{-}$and strong salt-out effect [56]. The obtained results indicate that even a small excess of $\mathrm{NaOH}$ to one hydroxyl group of diol in the molar ratio of $\mathrm{NaOH}$ : $\mathrm{BDO}$ equaling 0.6 was enough to suppress the formation of an allyl alcohol and diallyl ether (entries 3 and 4). Moreover, under those conditions, the expected value of 4-allyloxybutan-1-ol selectivity of $98 \%$ was noted, however, it is clear that a yield of $51 \%$ is insufficient for the productive process (entry 4 ). On the other hand, the better efficiency of the allylation with the yields of allyloxyalcohol of $72 \%$ after $6 \mathrm{~h}$ or above $84 \%$ for $8 \mathrm{~h}$ was noted for the equimolar molar ratio of $\mathrm{NaOH}: \mathrm{BDO}$ (entries 6-8). However, the values of ABO selectivity as high as $96 \%$ or below $90 \%$, respectively, were too low to achieve the high-purity product via distillation under reduced pressure. The further increasing of $\mathrm{NaOH}$ loading up to 1.5 of the $\mathrm{NaOH}: \mathrm{BDO}$ molar ratio, likewise as using solid $\mathrm{NaOH}$ in the molar ratio of $\mathrm{NaOH}: \mathrm{BDO}=0.6$ were unfavorable due to rapid solidification of the reaction mixture in the deprotonation step.

Next, on the assumption that the relatively low loading of $1 \mathrm{~mol} \%$ of $\mathrm{Bu}_{4} \mathrm{~N}^{+} \mathrm{HSO}_{4}{ }^{-}$ as PT catalysts might be responsible for the appreciable loss of ABO selectivity; 10-fold lowering the catalyst amount was verified. It became obvious that under-developed reaction conditions with the use of $\mathrm{Bu}_{4} \mathrm{~N}^{+} \mathrm{HSO}_{4}{ }^{-}$of $0.1 \mathrm{~mol} \%$ during $6 \mathrm{~h}$, the reaction could be decelerated on the mono-O-allyl substitution step, but the yield values of $54 \%$ or $57 \%$ were significantly low (entry 10 and 13). Thereafter, the selectivity decreased to $94-95 \%$ for the prolonged reaction time up to $10 \mathrm{~h}$ (entry 11 and 12, 14 and 15). Thus, in order to fully verify the catalyst effect in the studied process, we finally explored the allylation without $\mathrm{Bu}_{4} \mathrm{~N}^{+} \mathrm{HSO}_{4}{ }^{-}$(entries 16-19). As was mentioned above, the excellent results of mono-O-allyl derivative selectivity of $99 \%$ and a yield of $88 \%$ were obtained under non-catalyzed conditions but the very long reaction time of $48 \mathrm{~h}$ practically excludes the possibility of industrial application (Figure 1a, entry 16-17). Hence, considering findings of the key role of the salting-out effect in the facilitation of the extraction of organic salts from the aqueous to the organic phase and, in consequence, in acceleration substitution reaction rate, the reaction was carried out in the presence of $\mathrm{NaCl}$. Indeed, performing the reaction without $\mathrm{PT}$ catalysts but with a low amount of $\mathrm{NaCl}$ in the molar ratio to $\mathrm{BDO}$ of 0.5 caused a substantial increase in the ABO yield within $6 \mathrm{~h}$ (entry 18). Besides significant difficulties in the separation of organic products from the three-phase post-reaction mixture, the addition of bigger loading of $\mathrm{NaCl}$ resulted in a strong salt-out effect and the reduction in the selectivity (entry 19).

During our studies, problems associated with efficient phase separation and purification of the 4-allyloxybutan-1-ol from the reaction mixture were also solved. Namely, the other solvents have been considered to improve operational simplicity leading to faster, cleaner, and safer procedures. Unfortunately, the elimination of organic solvents was not possible due to the use of an excess of high volatile allyl chloride. Therefore, according to the literature data, that the solvent polarity has no substantial effect on the reaction course [58], toluene was successfully replaced by cyclohexane, with a value of solubility in water of $5.5 \mathrm{mg} / 100 \mathrm{~g} \mathrm{H}_{2} \mathrm{O}$ at $25^{\circ} \mathrm{C}$, thus, ca. 10 -fold lower than toluene $(52.6 \mathrm{mg} / 100 \mathrm{~g}$ $\mathrm{H}_{2} \mathrm{O}$ at $25^{\circ} \mathrm{C}$ ) (it should be pointed out that the inexpensive and easily available hexane with solubility in water of $0.95 \mathrm{mg} / 100 \mathrm{~g} \mathrm{H}_{2} \mathrm{O}$ at $25^{\circ} \mathrm{C}$ was excluded due to its lower boiling point temperature and higher volatility). As can be seen, in the case of using cyclohexane, practically the same results regarding $\mathrm{ABO}$ selectivity and yield were noted (compare entries 10-12 and 13-15). Importantly, the direct separation of aqueous and organic phases after reaction and the extraction of allyloxyalcohol from the aqueous phase (practically quantitative) occurred effectively and significant faster (ca. 3-4-fold)-the isolation yields of $\mathrm{ABO}$ were at least $10 \%$ higher than in toluene with a 3-fold lower volume of solvent. 
Summarizing, the research results presented above clearly indicate that key factors affecting the high selective (at least $98 \%$ ) and technologically useful synthesis of 4-allyloxybutan-1-ol under PTC conditions are as follow: (1) a separate deprotonation step within $15 \mathrm{~min}$ at a temperature of $50{ }^{\circ} \mathrm{C}$, (2) $50 \% \mathrm{NaOH}(\mathrm{aq})$ in the equimolar molar ratio of $\mathrm{NaOH}: \mathrm{BDO}$, (3) a minimal concentration of PT catalyst of $0.1 \mathrm{~mol} \%$, (4) a shorter reaction time, and (5) cyclohexane as solvent. However, under those conditions, the yield of 4-allyloxybutan-1-ol still was relatively low.

Therefore, for further optimization of the mono-O-allylation process we explored the catalytic activity of several commercial available symmetrical as well as nonsymmetrical tetraalkylammonium (TAA) salts (chloride or bromide) containing alkyl groups with a different number of carbon atoms in straight chains such as: tetramethylammonium bromide $\left(\mathrm{Me}_{4} \mathrm{~N}^{+} \mathrm{Br}^{-}\right)$, tetra- $n$-butylammonium bromide $\left(\mathrm{Bu}_{4} \mathrm{~N}^{+} \mathrm{Br}^{-}\right)$, methyltrioctylammonium bromide $\left(\mathrm{MeOc}_{3} \mathrm{~N}^{+} \mathrm{Br}^{-}\right)$, dodecyltrimethlammonium bromide $\left(\mathrm{Me}_{3} \mathrm{DoN}^{+} \mathrm{Br}^{-}\right)$, tetraethylammonium chloride $\left(\mathrm{Et}_{4} \mathrm{~N}^{+} \mathrm{Cl}^{-}\right)$, trimethylphenylammonium chloride $\left(\mathrm{Me}_{3} \mathrm{PhN}^{+} \mathrm{Cl}^{-}\right)$, methyltrioctylammonium chloride $\left(\mathrm{MeOc}_{3} \mathrm{~N}^{+} \mathrm{Cl}^{-}\right)$, dimethyldioctadecyl ammonium chloride $\left(\mathrm{Me}_{2}(\mathrm{R})_{2} \mathrm{~N}^{+} \mathrm{Cl}^{-}\right.$, where $\mathrm{R}$ is a mixture of homologs with a chain length of $\left.\mathrm{C}_{16}-\mathrm{C}_{18}\right)$. The screening of PT catalysts was conducted under the same reaction conditions with minimal loading of PT catalyst of $0.1 \mathrm{~mol} \%$ within a short time of $6 \mathrm{~h}$ in the presence of $50 \%$ $\mathrm{NaOH}(\mathrm{aq})$ at the equimolar molar ratio of $\mathrm{NaOH}: \mathrm{BDO}$ (the other parameters are given in Table 1, entry 13) and the obtained selectivity results and the yield of 4-allyloxybutan-1-ol are depicted graphically in Figure 2, together with the result without the catalyst (Figure 1a) and for $\mathrm{Bu}_{4} \mathrm{~N}^{+} \mathrm{HSO}_{4}{ }^{-}$(entry 13 in Table 1) for comparison.

First, it is clear, that all tested PT catalysts, except for TAA salts having long-chain alkyl groups such as $\mathrm{Me}_{3} \mathrm{DoN}^{+} \mathrm{Br}^{-}(5)$ and $\mathrm{Me}_{2}(\mathrm{R})_{2} \mathrm{~N}^{+} \mathrm{Cl}^{-}$(where $\mathrm{R}=$ alkyl group with the chain length of $\mathrm{C}_{16}-\mathrm{C}_{18}$ ) (9), exhibited moderate catalytic activity in the studied mono-O-allylation reaction conditions. What is important, the selectivity of $\mathrm{ABO}$ was almost quantitative $(99 \%)$ or quantitative $(100 \%)$, however, the yield values equaled a maximal of $66 \%$. Generally, the TTA chlorides $(6,7,8)$ were slightly less active than those with bromide anion $(2,3,4)$. The yields in the range of $55-57 \%$ or $59-66 \%$, respectively, were noted (Figure 2), which is in good correlation with the higher hydration energy of chloride anion in comparison to less hydrophilic bromide anion $[54,56]$. Surprisingly, the ammonium cation with methyl, ethyl, butyl, or phenyl groups, significantly differ in their lipophilicity, with practically no effect on the TAA catalytic activity. The visible higher $\mathrm{ABO}$ yields were determined for TAA with trioctylammonium cation, but the TAA with longer chains of twelve units and above sixteen do not act as a PT catalyst (probably due to high lipophilicity of ammonium cations, they remain preferentially in the organic phase, resulting in unfavorable extraction capability and, in consequence, decelerating or stopping the PT catalysis [53-56]). The PT catalyst with the highest activity ( $66 \%$ of the yield) was $\mathrm{MeOc}_{3} \mathrm{~N}^{+} \mathrm{Br}^{-}$(4). Interestingly, the activity of the revealed PT catalyst was substantially higher than $\mathrm{Bu}_{4} \mathrm{~N}^{+} \mathrm{HSO}_{4}{ }^{-}$, postulated by us previously [44].

Although the study on the mechanism of PTC mono-O-allylation was not planned in this work, our experimental results suggested that the reaction of butane-1,4-diol with allyl chloride in the studied PTC/concentrated $\mathrm{NaOH}(\mathrm{aq})$ system proceeds mainly via the interfacial mechanism, proposed by Makosza $[54,55]$. However, considering the lower $\mathrm{pKa}$ value of butane-1,4-diol of 14.5 [57], and according to the general instructions that organic acids with a pKa range $18<\mathrm{x}<25$ undergo PTC reaction in an interfacial manner, the Starks' extraction mechanism cannot be ruled out. However, the full understanding of the structural features that lead to PT catalytic activity and selectivity of TAA salts are much more complicated and require detailed research on both physical (mass transport between phases) and chemical (the interaction and correlation of reactivity of all ion reagents) aspects [53-56]. Instead, our attention became focused on the real effectiveness of the discovered $\mathrm{MeOc}_{3} \mathrm{~N}^{+} \mathrm{Br}^{-}$(4) in the studied model reaction. The influence of the minimal concentration of PT catalyst in the range of $0.1 \mathrm{~mol} \%$ to $0.7 \mathrm{~mol} \%$, sufficient to maintain the 
maximal selectivity to the mono-O-allylation product with the highest possible yield, was evaluated within a reaction time of $6 \mathrm{~h}$ or $8 \mathrm{~h}$ (Figure 3).

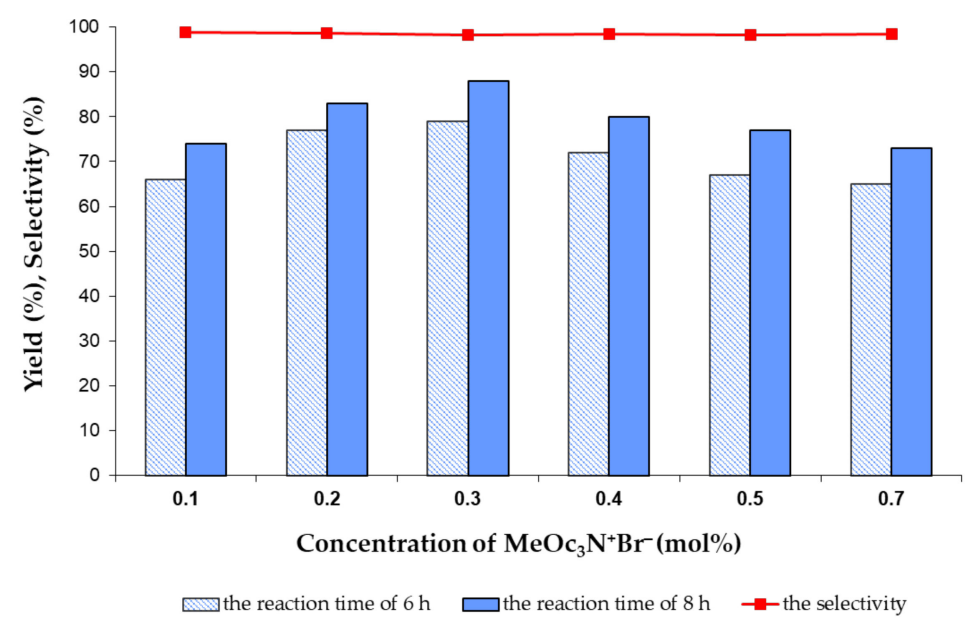

Figure 3. The effect of the $\mathrm{MeOc}_{3} \mathrm{~N}^{+} \mathrm{Br}^{-}$concentration on the mono-O-allylation of butane-1,4-diol by allyl chloride toward 4-allyloxybutan-1-ol in the presence of $50 \% \mathrm{NaOH}(\mathrm{aq})$ (the reaction conditions: see Table 1, entry 13).

It was found that the $O$-allylation reaction occurred very selective toward desired 4-allyloxybutan-1-ol, independently of the $\mathrm{MeOc}_{3} \mathrm{~N}^{+} \mathrm{Br}^{-}$concentration and the reaction time of $6 \mathrm{~h}$ or $8 \mathrm{~h}$. As expected, the yield values were slightly lower after $6 \mathrm{~h}$ than those for $8 \mathrm{~h}$. Moreover, a nonlinear relationship was observed between the yield and the $\mathrm{MeOc}_{3} \mathrm{~N}^{+} \mathrm{Br}^{-}$concentration. Namely, the progressive increase in the ABO amounts for lower loadings of $\mathrm{MeOc}_{3} \mathrm{~N}^{+} \mathrm{Br}^{-}$up to $0.3 \mathrm{~mol} \%$ was determined, which then gradually decreased using higher concentrations in the range of $0.4 \mathrm{~mol} \%$ to $0.7 \mathrm{~mol} \%$. Therefore, these results also tentatively confirm the interfacial mechanism of mono- $\mathrm{O}$-allylation under studied conditions. As can be seen, the best selective productivity of discovered PT catalytic system of $\mathrm{MeOc}_{3} \mathrm{~N}^{+} \mathrm{Br}^{-} / 50 \% \mathrm{NaOH}(\mathrm{aq})$ with the $\mathrm{ABO}$ yield of $88 \%$ was noted at the $\mathrm{MeOc}_{3} \mathrm{~N}^{+} \mathrm{Br}^{-}$concentration of $0.3 \mathrm{~mol} \%$ and relatively short reaction time of $8 \mathrm{~h}$. Moreover, under these conditions, the minimal formation of allyl chloride hydrolysis by-products $\leq 1 \%$ was noted. To our best knowledge, this is the first successful example of using of $\mathrm{MeOc}_{3} \mathrm{~N}^{+} \mathrm{Br}^{-}$in the mono-O-allylation reaction and technologically attractive, highly selective and yield PTC procedure.

\subsection{Mono-O-Allylation Reaction under Solvent-Free Non-Catalytic Conditions}

Although the PTC methodology has been considered the most efficient and general green technology [52-56] and provided excellent selectivity and yield results of 4-allyloxybutane-1-ol, we simultaneously conducted the study on the mono-O-allylation reaction without PT catalysts and without the organic solvent. First, due to the exothermal nature of allylation reaction, the allyl chloride was a key substrate and the excess of butan-1,4-diol was applied. This manner allows for practically full elimination of allyl chloride emission. According to the fact that water is one of the reaction products, formed in an amount equal to the allyl chloride conversion, the deprotonation of diol was proceeded by the solid $\mathrm{NaOH}$ for the prevention of the allyl chloride hydrolysis, the two phases formation, and the water using minimalization.

Generally, the reaction was carried out by the one-pot and two-step (deprotonation/allylation) methodology with an excess of BDO (the molar ratio of BDO:AC $=3$ ) at the temperature of $50^{\circ} \mathrm{C}$. The deprotonation step was conducted until the solid $\mathrm{NaOH}$, used in the molar ratio to allyl chloride of 1-1.1, was completely dissolved. In turn, in the allylation step, the reaction time required to obtain the highest conversion of allyl chloride was determined. The course of the allylation was monitored by a regular sampling in time 
and analysis by the gas chromatography. The reaction progress was monitored in terms of the conversion of allyl chloride $\left(\alpha_{A C}\right)$, the selectivity and yield of the 4-allyloxybutan-1-ol $\left(\mathrm{S}_{\mathrm{ABO}}, \mathrm{Y}_{\mathrm{ABO}}\right)$, and the yields of $\mathrm{AC}$ hydrolysis products such as allyl alcohol $\left(\mathrm{Y}_{\mathrm{AA}}\right)$ and diallyl ether $\left(\mathrm{Y}_{\mathrm{AE}}\right)$. The selected results are presented in Table 2.

Table 2. The solvent-free mono-O-allylation of butane-1,4-diol by allyl chloride to 4-allyloxybutan-1-ol $(\mathrm{ABO})$ in the presence of solid $\mathrm{NaOH}$ under non-catalytic conditions ${ }^{1}$.

\begin{tabular}{ccccccc}
\hline Entry & $\begin{array}{c}\text { NaOH:AC } \\
\text { Molar Ratio }\end{array}$ & $\begin{array}{c}\text { I Step } \\
\text { Time } \mathbf{( m i n . ) / 5 0}{ }^{\circ} \mathbf{C}\end{array}$ & $\begin{array}{c}\text { II Step } \\
\text { Time (h)/50 }{ }^{\circ} \mathbf{C}\end{array}$ & $\begin{array}{c}\boldsymbol{\alpha}_{\mathrm{AC}} \\
\mathbf{( \% )}\end{array}$ & $\begin{array}{c}\mathbf{S}_{\mathrm{ABO}} \\
\mathbf{( \% )}\end{array}$ & $\begin{array}{c}\mathbf{Y}_{\mathrm{ABO}} \\
\mathbf{( \% )}\end{array}$ \\
\hline 1 & 1 & 50 & 3 & 91 & 98.9 & 90 \\
2 & 1.05 & 75 & 2.5 & 97 & 99.0 & 96 \\
3 & 1.1 & 90 & 2 & 100 & 99.2 & 99.2 \\
4 & 1.1 & 80 & 2 & 100 & 99.0 & 99 \\
$5^{3}$ & 1.1 & 100 & 2.5 & $\sim 100$ & 99.3 & 99.3 \\
\hline
\end{tabular}

${ }^{1}$ The reaction conditions: 0.3 mole scale of $\mathrm{AC}$, the molar ratio of $\mathrm{BDO}: \mathrm{AC}=3$, mechanical paddle stirrer. ${ }^{2}$ The recycled $\mathrm{BDO}$ was used (the mass ratio of recycled $\mathrm{BDO}$ :fresh $\mathrm{BDO}=$ ca. 2 ). ${ }^{3}$ The 3 -moles scale of $\mathrm{AC}$.

Initially, the solid $\mathrm{NaOH}$, used in an equimolar molar ratio of $\mathrm{NaOH}$ : $\mathrm{AC}$, fully reacted with heated up to $50{ }^{\circ} \mathrm{C}$ excess of butane-1,4-diol during ca. $50 \mathrm{~min}$ and then the allyl chloride was carefully added dropwise. Due to the exothermal nature of the allylation reaction, the rise in the reaction temperature was scrupulously controlled. The maximal value of AC conversion of $91 \%$ together with almost quantitative ABO selectivity of ca. $99 \%$ was noted after $3 \mathrm{~h}$ (Table 2, entry 1). Encouraged by this finding, we conducted the reaction with a slightly higher amount of $\mathrm{NaOH}$, namely in the molar ratio of $\mathrm{NaOH}$ :AC equaled 1.05 and 1.1, to ensure complete the AC conversion toward 4-allyloxybutane-1-ol. First, it was found that utilizing a low excess of $\mathrm{NaOH}$ of 1.05 and 1.1 contributed to a longer time to reach its full dissolution up to $75 \mathrm{~min}$ and $90 \mathrm{~min}$, respectively, but simultaneously, the reaction times were reduced by $30 \mathrm{~min}$ (entries 2 and 3). The use of the 1.05 excess of $\mathrm{NaOH}$ provided satisfactory results of $\mathrm{ABO}$ yield of $96 \%$ (entry 2). However, surprisingly, under the 1.1 excess of $\mathrm{NaOH}$, the mono-O-allylation of butane-1,4-diol ran spectacularly fast and selectively, leading to the practically quantitative yield of $\mathrm{ABO}$ in a very short reaction time of $2 \mathrm{~h}$ and an overall process time of $3.5 \mathrm{~h}$ (entry 3). Importantly, in this methodology, the AC hydrolysis practically did not occur-traces of hydrolysis by-products of $<0.1 \%$ were barely detected. Optionally, the post-reaction mixture can be neutralized by $10 \% \mathrm{HCl}$ solution. The distillation of crude allyloxyalcohol allows obtaining a highly pure product (purity $>99 \%$ ) with an isolated yield value of ca. 95\%.

Moreover, to improve the technological usefulness of this method, attempts of directly recycling the unreacted $\mathrm{BDO}$ were undertaken. We established that the mono-O-allylation occurred with practically the same results, except the fact that BDO contained ca. 7.5\% of water after the separation by distillation. Therefore, it is reasonable to suggest that repeated use of the unreacted substrate increases the overall amount of water in the reaction systems, which eventually could have a negative effect on AC hydrolysis as well as on the water content in the allyloxyalcohol product. Therefore, the dehydrating of unreacted BDO by the azeotropic distillation method may be necessary to maintain the appropriate parameters needed to ensure the correct course of the process. Furthermore, the significant technological advantage of the developed procedure is the possibility of its easy scaling-up potential. The process was scaled up 10 times without any problems. As can be seen, except for the longer time needed for complete dissolution of $\mathrm{NaOH}$, the mono-O-reaction results were practically the same as in the small-scale experiment (compare entry 4 and entry 5). Therefore, it can be concluded that this highly effective method has a potential industrial application. For this reason, we additionally confirmed its usefulness for the full $O$-allylation of butane-1,4-diol toward 1,4-bisallyloxybutane. The reaction was conducted on the scale of 2 moles of BDO with stochiometric amounts of organic reagents and with low excess of the solid $\mathrm{NaOH}$ in the molar ratio of $\mathrm{NaOH}: \mathrm{AC}$ of 
1.05 within $2 \mathrm{~h}$. Again, the almost quantitative values of the conversion of allyl chloride and the yield of 1,4-bisallyloxybutane were noted. In light of the above, it seems that the further investigation of other diols for the production of valuable allyloxyalcohol derivatives, relatively unexplored so far, is reasonable from a technological point of view. However, in the case of nonvolatile diols or polyols, the possibility of their recycling under atmospheric or reduced pressure should be taken into account (their boiling point values cannot be too high).

\section{Materials and Methods}

\subsection{General}

Butan-1,4-diol (purity $>98 \%$ ), allyl chloride (purity $>96 \%$ ), $\mathrm{NaOH}$ pellets (diameter 3-5 mm, purity $>98 \%$ ), $\mathrm{NaCl}$, cyclohexane (purity $>98 \%$ ), toluene (purity $>97 \%$ ), anhydrous magnesium sulfate and PT catalysts (purity $>97-98 \%$ ) such as tetramethylammonium bromide $\left(\mathrm{Me}_{4} \mathrm{~N}^{+} \mathrm{Br}^{-}\right)$, tetra- $n$-butylammonium bromide $\left(\mathrm{Bu}_{4} \mathrm{~N}^{+} \mathrm{Br}^{-}\right)$, methyltrioctylammonium bromide $\left(\mathrm{Bu}_{4} \mathrm{~N}^{+} \mathrm{Br}^{-}\right)$, dodecyltrimethlammonium bromide $\left(\mathrm{Me}_{3} \mathrm{DoN}^{+} \mathrm{Br}^{-}\right)$, tetraethylammonium chloride $\left(\mathrm{Et}_{4} \mathrm{~N}^{+} \mathrm{Cl}^{-}\right)$, trimethylphenylammonium chloride $\left(\mathrm{Me}_{3} \mathrm{PhN}^{+} \mathrm{Cl}^{-}\right)$, methyltrioctylammonium chloride $\left(\mathrm{MeOc}_{3} \mathrm{~N}^{+} \mathrm{Cl}^{-}\right)$, dimethyldioctadecyl ammonium chloride $\left(\mathrm{Me}_{2}(\mathrm{R})_{2} \mathrm{~N}^{+} \mathrm{Cl}^{-}\right.$, where $\mathrm{R}$ is the mixture of homologs with a chain length of $\mathrm{C}_{16}-\mathrm{C}_{18}$, Arquad ${ }^{\circledR} 2 \mathrm{HT}$ ), allyl alcohol, diallyl ether and cyclohexanone analytical standard were purchased at Fluka, Merck, Aldrich or POCh Gliwice and were used as supplied.

The reaction mixtures were quantitatively analyzed by GC by the internal standard calibration method with cyclohexanone as analytical standard using the Trace U1tra GC (Thermo Fisher Scientific, Basel, Switzerland) with the flame ionization detector (FID), helium as carrier gas, and column Rtx-1 (Restek, Bellefonte, PA, USA) with 100\% polydimethyl-polysiloxane as stationary phase (length: $30 \mathrm{~m}$, diameter: $0.53 \mathrm{~mm}$, thickness of the film: $1.5 \mu \mathrm{m})$ and program temperature $\left(35^{\circ} \mathrm{C}\right.$ for $6 \mathrm{~min}$, heat ramp $5^{\circ} \mathrm{C} / \mathrm{min}$ to $130{ }^{\circ} \mathrm{C}$ held for $7 \mathrm{~min}$ ). Under these conditions, retention times ( $\mathrm{min}$ ) were as follows: 3.14 allyl chloride; 3.35 allyl alcohol, 4.23 cyclohexane, 5.15 butane-1,4-diol, 7.78 diallyl ether, 10.98 cyclohehanone, 12.74 -allyloxybutan-1-ol, 16.82 1,4-bisalliloxybutane. Typically, on the basis of on percentage of organic components of the post-reaction mixture, the $\mathrm{O}$-allylation progress was evaluated in terms of the selectivity and yield of the 4-allyloxybutan-1-ol and the yields of by-products such as 1,4-bisallyloxybutanol, allyl alcohol and diallyl ether.

Typically, in the small-scale experiments using 0.3 moles of the key substrate, all the $O$-allylation reactions were performed in lab-scale four-necked, round bottom, jacketed glass reactors with bottom drain valve and $500 \mathrm{~mL}$ capacity, equipped with a mechanical stirrer paddle, reflux condenser, thermometer, and dropping funnel. In the large-scale experiments of the 3 moles of the key substrate, a reactor capacity of $2.5 \mathrm{~L}$ was used. In turn, the crude product was purified by vacuum distillation on a semi-micro Fischer apparatus with 40 or 70 theoretical plates. The characteristic and spectroscopic data of the synthetized allyloxy products such as 4-allyloxybutan-1-ol and 1,4-bisallyloxybutanol were given in a previous publication [44], i.e.:

- 4-alliloxybutan-1-ol: bp. $62{ }^{\circ} \mathrm{C} / 0.5 \mathrm{mmHg} ;{ }^{1} \mathrm{H} \mathrm{NMR}\left(400 \mathrm{~Hz}, \mathrm{CDCl}_{3}\right): 5.82-5.74$ (m, $\left.1 \mathrm{H}, \mathrm{CH}_{2}=\mathrm{CH}-\right), 5.15-5.12\left(\mathrm{~d}, J=17.2 \mathrm{~Hz}, 1 \mathrm{H}_{(E)}, \mathrm{CH}_{2}=\mathrm{CH}-\right), 5.08-5.03(\mathrm{~d}, J=10.4 \mathrm{~Hz}$, $\left.1 \mathrm{H}_{(\mathrm{Z})}, \mathrm{CH}_{2}=\mathrm{CH}-\right), 4.30(\mathrm{~s}, 1 \mathrm{H},-\mathrm{OH}), 3.85\left(\mathrm{~d}, \mathrm{~J}=5.0 \mathrm{~Hz}, 2 \mathrm{H},=\mathrm{CH}_{-} \mathrm{CH}_{2}-\mathrm{O}-\right), 3.47(\mathrm{t}$, $\left.J=11.4 \mathrm{~Hz}, 2 \mathrm{H},-\mathrm{CH}_{2}-\mathrm{OH}\right), 3.33\left(\mathrm{t}, \mathrm{J}=12.3 \mathrm{~Hz}, 2 \mathrm{H},-\mathrm{O}-\mathrm{CH}_{2}-\right), 1.56-1.50\left(\mathrm{~m}, 4 \mathrm{H},-\mathrm{CH}_{2}-\right)$; ${ }^{13} \mathrm{C} \mathrm{NMR}\left(400 \mathrm{~Hz}, \mathrm{CDCl}_{3}\right) 135.5\left(\mathrm{CH}_{2}=\mathrm{CH}-\right), 117.1\left(\mathrm{CH}_{2}=\mathrm{CH}-\right), 72.3\left(=\mathrm{CH}-\mathrm{CH}_{2}-\mathrm{O}-\right)$, $70.6\left(-\mathrm{CH}_{2}-\mathrm{O}-\mathrm{CH}_{2}-\right), 62.8\left(-\mathrm{CH}_{2}-\mathrm{OH}\right), 29.8,26.7\left(-\mathrm{CH}_{2}-\mathrm{CH}_{2}-\right) ; \mathrm{MS}(\mathrm{m} / q$, int $(\%)): 130$ (M+ 0.03\%); 89 (13); 73 (54); 71 (84); 58 (26); 57 (44); 55 (77); 43 (52); 41 (100); 39 (39); 31 (38); 29 (18); refractive index $\left(24.5^{\circ} \mathrm{C}\right): 1.4400$, density $\left(20^{\circ} \mathrm{C}\right): 0.9288 \mathrm{~g} / \mathrm{cm}^{3}$;

- 1,4-bisalliloxybutane: bp. $52^{\circ} \mathrm{C} / 0.5 \mathrm{mmHg}$; $1 \mathrm{H} \mathrm{NMR}\left(400 \mathrm{~Hz}, \mathrm{CDCl}_{3}\right): 5.82-5.76$ (m, $\left.2 \mathrm{H}, \mathrm{CH}_{2}=\mathrm{CH}-\right), 5.18-5.13\left(\mathrm{~d}, J=17.3 \mathrm{~Hz}, 2 \mathrm{H}_{(E)}, \mathrm{CH}_{2}=\mathrm{CH}-\right), 5.05-5.01(\mathrm{~d}, J=10.4 \mathrm{~Hz}$, $\left.2 \mathrm{H}_{(\mathrm{Z})}, \mathrm{CH}_{2}=\mathrm{CH}-\right), 3.84\left(\mathrm{~m}, 4 \mathrm{H},=\mathrm{CH}-\mathrm{CH}_{2}-\mathrm{O}-\right), 3.33\left(\mathrm{~m}, 4 \mathrm{H},-\mathrm{O}-\mathrm{CH}_{2}-\right), 1.65\left(4 \mathrm{H},-\mathrm{CH}_{2}-\right)$; ${ }^{13} \mathrm{C} \mathrm{NMR}\left(400 \mathrm{~Hz}, \mathrm{CDCl}_{3}\right) 135.1\left(\mathrm{CH}_{2}=\mathrm{CH}-\right), 116.3\left(\mathrm{CH}_{2}=\mathrm{CH}-\right), 71.6\left(=\mathrm{CH}-\mathrm{CH}_{2}-\mathrm{O}-\right)$, 
$70.6\left(-\mathrm{CH}_{2}-\mathrm{O}-\mathrm{CH}_{2}-\right), 26.4\left(-\mathrm{CH}_{2}-\mathrm{CH}_{2}-\right)$; $\mathrm{MS}(\mathrm{m} / q$, int (\%)): $170(\mathrm{M}+0.002 \%) ; 129$ (11); 113 (12); 71 (100); 55 (19); 43 (17); 41 (78); 39 (19); 29 (7); refractive index $\left(24.5^{\circ} \mathrm{C}\right)$ : 1.4360 , density $\left(20^{\circ} \mathrm{C}\right): 0.8805 \mathrm{~g} / \mathrm{cm}^{3}$.

\subsection{The Procedure of O-Allylation Reaction under PTC Conditions}

The reactions were performed on a small scale. The reactor was charged with 0.3 mole (27 g) of butan-1,4-diol and the $35 \%$ or $50 \% \mathrm{NaOH}$ aqueous solution and amount of $\mathrm{NaOH}$ in the molar ratio of $\mathrm{NaOH}: \mathrm{BDO}=0.6,1$ or 2.5 as given in Table 1 . The reaction mixture was vigorously stirred (ca. $600 \mathrm{rpm}$ ) and heated to $50{ }^{\circ} \mathrm{C}$ or $90^{\circ} \mathrm{C}$ and maintained at that temperature for $15 \mathrm{~min}$ or $30 \mathrm{~min}$, respectively, if the separated deprotonation step was conducted, and cooled to $50{ }^{\circ} \mathrm{C}$, if necessary. Subsequently, during stirring, the PT catalyst in the amount of $0.1 \mathrm{~mol} \%$ or $1 \mathrm{~mol} \%$ and the mixture of the allyl chloride $(86 \mathrm{~mL})$ in solvent (129 mL) (toluene or cyclohexane) and optionally $\mathrm{NaCl}$ were introduced. The reaction mixture was moderately stirred (ca. $300 \mathrm{rpm}$ ) at a temperature of $50{ }^{\circ} \mathrm{C}$ for a suitable time given in Table 1 and then left to cool down and to separate the phases. The aqueous phase was separated and extracted with solvent (toluene: $3 \times 30 \mathrm{~mL}$ or cyclohexane: $3 \times 10 \mathrm{~mL}$ ). The combined organic phases were dried over anhydrous $\mathrm{MgSO}_{4}$, filtered, and analyzed by GC. The volatile components were distilled off on a rotatory evaporator. The crude product was purified by vacuum distillation and 4-allyloxybuan-1-ol with purity $>98 \%$ was obtained with the isolated yield values of ca. $7-10 \%$ lower than those determined by GC.

\subsection{The Procedure of O-Allylation Reaction under Solvent-Free Non-Catalytic Conditions}

For the small-scale $O$-allylation reactions, 0.9 moles $(81 \mathrm{~g})$ of butane-1,4-diol was placed in the reactor and heated to $50{ }^{\circ} \mathrm{C}$. Then, during vigorously stirring (ca. $600 \mathrm{rpm}$ ), the solid $\mathrm{NaOH}$ was added gradually in several portions. After the $\mathrm{NaOH}$ was completely dissolved, 0.3 moles ( $23 \mathrm{~g}$, $24.5 \mathrm{~mL}$ ) of allyl chloride was carefully introduced dropwise due to the exothermic nature of the allylation reaction while ensuring that the temperature did not exceed $60{ }^{\circ} \mathrm{C}$. The reaction was kept under stirring for a suitable time of $2-3 \mathrm{~h}$ (Table 2) required to obtain the highest conversion of allyl chloride. The post-reaction mixture was left overnight to cool and to separate the organic liquid and solid of $\mathrm{NaCl}$ phases. Next, the organic reaction mixture was optionally neutralized by $10 \% \mathrm{HCl}$ solution. The overall $\mathrm{NaCl}$ precipitate was separated by filtration. The unreacted butane-1,4-diol was distilled off under atmospheric pressure and crude 4-allyloxybunat-1-ol was purified by vacuum distillation (purity > 99\%). For the large-scale experiment, 3 moles ( $230 \mathrm{~g}$ ) of allyl chloride, 9 moles (810 g) of butane-1,4-diol, and $132 \mathrm{~g}$ of solid $\mathrm{NaOH}$ were used and the reaction was conducted exactly via methodology presented above within $2 \mathrm{~h}$ after complete dissolution of $\mathrm{NaOH}$ without any problems and the same results were obtained.

\section{Conclusions}

In this work, the basic technological assumptions of two effective methods for the highly selective and productive synthesis of model allyloxyalcohol were developed using cost-efficient commercially available starting materials. The major advantages of improved PTC methodology with using a new catalyst of $\mathrm{MeOc}_{3} \mathrm{~N}^{+} \mathrm{Br}^{-}$and $50 \% \mathrm{NaOH}(\mathrm{aq})$ are the minimalization of alkaline wastewater, the practical elimination of hydrolysis of allyl chloride, and simplified and safety of work-up. However, other features of this method that may represent significant disadvantages include using excess volatile allyl chloride and organic solvent, the extraction of organic product and separation, recovery, and recycling of the catalyst from the product. On the other hand, the non-catalytic, solvent-free, and easily scalable method using solid $\mathrm{NaOH}$ and allyl chloride as key substrates substantially reduced the overall reaction time, the by-products production and the emission of toxic and flammable allyl chloride, the amount of used process water, and the formation of alkaline wastewater. Moreover, the practically quantitative yield of the desired allyloxyalcohol allowed to obtain a very good quality pure product, which is essential for its further special 
synthetic application. Therefore, this practical sustainable and cost-saving technology can be recommended for the synthesis of a wide range of industrially valuable allyloxyalcohols from easily recycled via distillation under atmospheric or reduced pressure polyols, also from renewable sources.

Funding: This research received no external funding.

Institutional Review Board Statement: Not applicable.

Informed Consent Statement: Not applicable.

Data Availability Statement: Not applicable.

Conflicts of Interest: The authors declare no conflict of interest.

\section{References}

1. Smith, M.B.; March, J. March's Advanced Organic Chemistry, 6th ed.; Wiley-Interscience: New York, NY, USA, 2007.

2. Godleski, S.A. Comprehensive Organic Synthesis; Pergamon: Oxford, UK, 1991; Volume 4, pp. 586-661.

3. Krähling, L.; Krey, J.; Jakobson, G.; Grolig, J.; Miksche, L. Allyl Compounds. In Ullmann's Encyclopedia of Industrial Chemistry; Wiley-VCH: Weinheim, Germany, 2000.

4. Schildknecht, C.E. Allyl Compounds and Their Polymers (Including Polyolefins); Wiley-Interscience: New York, NY, USA; London, UK, 1973.

5. Jensen, E.S.; Gatenholm, P.; Nanguneri, S.R.; Mathias, L. Effect of chemical structure of allyl ethers on polymerization and properties of multifunctional acrylate systems. J. Appl. Polym. Sci. 1991, 42, 2681. [CrossRef]

6. Yuan, H.; Lu, X.; Zeng, Z.; Yang, J.; Chen, Y. Allyl ether-modified unsaturated polyesters for UV/air dual-curable coatings. I: Synthesis and characterization of the oligomers and their cured films. J. Appl. Polym. Sci. 2004, 92, 2765-2770. [CrossRef]

7. Tehfe, M.A.; Louradour, F.; Lalevée, J.; Fouassier, J.-P. Photopolymerization Reactions: On the Way to a Green and Sustainable Chemistry. Appl. Sci. 2013, 3, 490-514. [CrossRef]

8. Rokicki, G.; Szymańska, E. Unsaturated Polyester Resins with Different Allyl Ethers as Crosslinking Built-In Monomers. J. Appl. Polym. Sci. 1998, 70, 2031-2039. [CrossRef]

9. Crivello, J.V.; Jo, K.D. Propenyl Ethers I. The Synthesis of Propenyl Ether Monomers. J. Polym. Sci. Part A Polym. Chem. 1993, 31, 1473-1482. [CrossRef]

10. Krompiec, S.; Kuźnik, N.; Urbala, M.; Rzepa, J. Isomerization of alkyl allyl and allyl silyl ethers catalyzed by ruthenium complexes. J. Mol. Catal. A Chem. 2006, 248, 98-209. [CrossRef]

11. Urbala, M. The effectiveness of ruthenium(II) complexes and ruthenium trichloride as pre-catalysts in solvent-free isomerization of model alkyl allyl ether. Appl. Catal. A Gen. 2010, 377, 27-34. [CrossRef]

12. Urbala, M.; Krompiec, S.; Penkala, M.; Danikiewicz, W.; Grela, M. Solvent-free Ru-catalyzed isomerization of allyloxyalcohols: Methods for highly selective synthesis of 1-propenyloxyalcohols. Appl. Catal. A Gen. 2013, 451, 101-111. [CrossRef]

13. Urbala, M. Solvent-free [Ru]-catalyzed isomerization of allyl glycidyl ether: The scope, effectiveness and recycling of catalysts, and exothermal effect. Appl. Catal. A Gen. 2015, 505, 382-393. [CrossRef]

14. Urbala, M. Highly Productive Synthesis of 1-Propenyloxybutan-1-ol Under Solvent-Free Homogeneous Ruthenium Catalyst Conditions. Catalysts 2020, 10, 1409. [CrossRef]

15. Bouvet-Marchand, A.; Chatard, C.; Graillot, A.; Boutevin, G.; Loubat, C.; Grossob, D. Influence of experimental parameters on the side reactions of hydrosilylation of allyl polyethers studied by a fractional factorial design. React. Chem. Eng. 2018, 3, 696-706. [CrossRef]

16. Konuraya, O.; Fernández-Francosa, X.; Ramisa, X.; Serrab, A. New allyl-functional catalytic comonomers for sequential thiolMichael and radical thiolene reactions. Polymer 2018, 138, 369-377. [CrossRef]

17. Nilsson, C.; Simpson, N.; Malkoch, M.; Johansson, M.; Malmström, E. Synthesis and thiol-ene photopolymerization of allyl-ether functionalized dendrimers. J. Polym. Sci. Part A Polym. Chem. 2008, 46, 1339-1348. [CrossRef]

18. Resetco, C.; Hendriks, B.; Badi, N.; Du Prez, F. Thiol-ene chemistry for polymer coatings and surface modification-Building in sustainability and performance. Mater. Horiz. 2017, 4, 1041-1053. [CrossRef]

19. Dutta, B.; Clarke, R.; Raman, S.; Shaffer, T.D.; Achola, L.; Nandi, P.; Suib, S.L. Lithium promoted mesoporous manganese oxide catalyzed oxidation of allyl ethers. Nat. Commun. 2019, 8, 655. [CrossRef] [PubMed]

20. Sutter, M.; Da Silva, E.; Duguet, N.; Raoul, Y.; Métay, E.; Lemaire, M. Glycerol Ether Synthesis: A Bench Test for Green Chemistry Concepts and Technologies. Chem. Rev. 2015, 115, 8609-8651. [CrossRef]

21. Rao, B.V.S.K.; Gangadhar, A.; Subbarao, R.; Lakshminarayana, G.A. Facile synthesis of rac-1-O-alkylglycerols. Org. Prep. Proced. Int. 1991, 23, 119-122. [CrossRef]

22. Shing, T.K.M.; Tai, V.W.F.; Tam, E.K.W. Practical and Rapid Vicinal Hydroxylation of Alkenes by Catalytic Ruthenium Tetraoxide. Angewandte Chemie 1994, 33, 2312-2313. [CrossRef]

23. Wang, Z.-M.; Zhang, X.-L.; Sharpless, K.B. Asymmetric dihydroxylation of aryl allyl ethers. Tetrahedron Lett. 1993, 34, 2267-2270. [CrossRef] 
24. Johansson, M.; Malmström, E.; Hult, A. Synthesis, characterization, and curing of hyperbranched allyl ether-maleate functional ester resins. J. Polym. Sci. A Polym. Chem. 1993, 31, 619-624. [CrossRef]

25. Stacy, M.T.; Nilsson, C.; Malmström, E.; Johansson, M. Thiolene networks and reactive surfaces via photoinduced polymerization of allyl ether functional hyperbranched polymers. Prog. Org. Coat. 2010, 67, 348-355. [CrossRef]

26. Das, A.; Mahanwar, P. A brief discussion on advances in polyurethane applications. Adv. Ind. Eng. Polym. Res. 2020, 3, 93-101. [CrossRef]

27. Ferris, C.; de Paz, M.V.; Galbis, J.A. Synthesis of functional sugar-based polyurethanes. Macromol. Chem. Phys. 2012, 213, 480-488. [CrossRef]

28. Galbis, J.A.; García-Martín, M.G.; de Paz, M.V.; Galbis, E. Synthetic polymers from sugar-based monomers. Chem. Rev. 2016, 116, 1600-1636. [CrossRef] [PubMed]

29. Shrestha, M.L.; Ionescu, M.; Wan, X.; Upshaw, T. Biobased Aromatic-Aliphatic Polyols by Thiol-Ene Reactions of Propoxylated Mercaptanized Cardanol. J. Renew. Mater. 2018, 6, 630-641. [CrossRef]

30. Besse, V.; Camara, F.; Voirin, C.; Auvergne, R.; Caillol, S.; Boutevina, B. Synthesis and applications of unsaturated cyclocarbonates. Polym. Chem. 2013, 4, 4545-4561. [CrossRef]

31. Mindemark, J.; Imholt, L.; Montero, J.; Brandell, D. Allyl ethers as combined plasticizing and crosslinkable side groups in polycarbonate-based polymer electrolytes for solid-state Li batteries. J. Polym. Sci. Part A Polym. Chem. 2016, 54, $2128-2135$. [CrossRef]

32. Olsén, P.; Odelius, K.; Albertsson, A.-C. Ring-Closing Depolymerization: A Powerful Tool for Synthesizing the AllyloxyFunctionalized Six-Membered Aliphatic Carbonate Monomer 2-Allyloxymethyl-2-ethyltrimethylene Carbonate. Macromolecules 2014, 47, 6189-6195. [CrossRef]

33. Niemczyk, E.M.; Gomez-Lopez, A.; Haler, J.R.N.; Frache, G.; Sardon, H.; Quintana, R. Insights on the Atmospheric-Pressure Plasma-Induced Free-Radical Polymerization of Allyl Ether Cyclic Carbonate Liquid Layers. Polymers 2021, 13, 2856. [CrossRef] [PubMed]

34. Urbala, M.; Antoszczyszyn, M. The synthesis of allyl ether functionalized siloxane monomers under ultrasonic irradiation at ambient conditions. Ultrason. Sonochem. 2004, 11, 409. [CrossRef]

35. Kuciński, K.; Hreczycho, G. Synthesis of novel bifunctional organosilicon dendrons via platinum-catalyzed hydrosilylation. Inorg. Chim. Acta 2017, 461, 233-238. [CrossRef]

36. Skrodzki, M.; Zaranek, M.; Witomska, S.; Pawluc, P. Direct Dehydrogenative Coupling of Alcohols with Hydrosilanes Promoted by Sodium tri(sec-butyl)borohydride. Catalysts 2018, 8, 618. [CrossRef]

37. Global Epichlorohydrin (ECH) Industry 2020. Available online: https://www.globenewswire.com/news-release/2020/08/08/2 075328/0/en/Global-Epichlorohydrin-ECH-Industry.html (accessed on 13 September 2021).

38. Obermeier, B.; Frey, H. Poly(ethylene glycol-co-allyl glycidyl ether)s: A PEG-Based Modular Synthetic Platform for Multiple Bioconjugation. Bioconjugate Chem. 2011, 22, 436-444. [CrossRef] [PubMed]

39. Satoh, T.; Ikeda, M.; Miura, M.; Nomura, M. Palladium-Catalyzed Etherification of Allyl Alcohols Using Phenols in the Presence of Titanium(IV) Isopropoxide. J. Org. Chem. 1997, 62, 4877. [CrossRef]

40. Saburi, H.; Tanaka, S.; Kitamura, M. Catalytic Dehydrative Allylation of Alcohols. Angezwandte Chemie 2005, 117, 1758-1760. [CrossRef]

41. Nakagawa, H.; Hirabayashi, T.; Sakaguchi, S.; Ishii, Y. Allylation of Alcohols and Carboxylic Acids with Allyl Acetate Catalyzed by $\left[\operatorname{Ir}(\operatorname{cod})_{2}\right]^{+} \mathrm{BF}_{4}-$ Complex. J. Org. Chem. 2004, 69, 3474-3477. [CrossRef]

42. Tang, H.; Tian, Y.B.; Cui, H.; Li, R.Z.; Zhang, X.; Niu, D. Site-switchable mono-O-allylation of polyols. Nat. Commun. 2020, 11, 5681. [CrossRef] [PubMed]

43. Kon, Y.; Fujitani, T.; Nakashima, T.; Murayamabc, T.; Ueda, W. Versatile etherification of alcohols with allyl alcohol by a titanium oxide-supported molybdenum oxide catalyst: Gradual generation from titanium oxide and molybdenum oxide. Catal. Sci. Technol. 2018, 8, 4618-4625. [CrossRef]

44. Antoszczyszyn, M.; Janus, E.; Urbala, M. Synthesis of mono- and diallyl ethers of 1,4-dihydroxybutane, Z-1,4-dihydroxy-2-butene and 1,4-dihydroxy-2-butyne. Pol. J. Appl. Chem. 1999, 43, 77-83.

45. Martysz, D.; Urbala, M.; Antoszczyszyn, M.; Pilawka, R. 1-Propenyl ethers of butanediol as effective modifiers of UV-cured epoxy coatings in cationic polymerization. Polimery 2002, 11-12, 849-851. [CrossRef]

46. Martysz, D.; Antoszczyszyn, M.; Urbala, M.; Krompiec, S.; Fabrycy, E. Synthesis of 1-propenyl ethers and their using as modifiers of UV-cured coatings in radical and cationic polymerization. Prog. Org. Coat. 2003, 46, 302-311. [CrossRef]

47. Czech, Z.; Urbala, M. UV-crosslinked acrylic pressure-sensitive adhesive systems containing unsaturated ethers. Polimery 2007, 6, 438-442. [CrossRef]

48. The global market of 1,4-butanediol. Available online: https://www.grandviewresearch.com/industry-analysis/1-4-butanediolmarket (accessed on 13 September 2021).

49. Rosales-Calderon, O.; Arantes, V.A. Review on commercial-scale high-value products that can be produced alongside cellulosic ethanol. Biotechnol. Biofuels 2019, 12, 240. [CrossRef]

50. Harmata, M.; Rashatasakhon, P.; Barnes, C.L. Intramolecular [4 + 3] cycloadditions-Stereochemical issues in the cycloaddition reactions of cyclopentenyl cations-A synthesis of (+)-dactylol. Can. J. Chem. 2006, 84, 1456-1469. [CrossRef] 
51. Crivello, J.V.; Yang, B.; Kim, W.-G. Chemoselective hydrosilations. I. Synthesis and photopolymerization of 1-propenyl ether functionalized siloxanes. J. Polym. Sci. Part A Polym. Chem. 1995, 33, 2415-2423. [CrossRef]

52. Halpern, M. Phase-Transfer Catalysis. In Ullmann's Encyclopedia of Industrial Chemistry; Wiley-VCH: Weinheim, Germany, 2002. [CrossRef]

53. Mąkosza, M. Phase-transfer catalysis. A general green methodology in organic synthesis. Pure Appl. Chem. 2000, 72, 1399-1403. [CrossRef]

54. Mąkosza, M.; Fedoryński, M. Phase Transfer Catalysis. Catal. Rev. Sci. Eng. 2003, 45, 321-367. [CrossRef]

55. Mąkosza, M.; Fedoryński, M. Interfacial Processes-The Key Steps of Phase Transfer Catalyzed Reactions. Catalysts 2020, 10, 1436. [CrossRef]

56. Albanese, D. Liquid-Liquid Phase Transfer Catalysis: Basic Principles and Synthetic Applications. Catal. Rev. Sci. Eng. 2003, 45, 369-395. [CrossRef]

57. Riddick, J.A.; Bunger, W.B.; Sakano, T.K. Organic Solvents: Physical Properties and Methods of Purification, 4th ed.; Wiley-Interscience: New York, NY, USA, 1986.

58. Morozova, N.V.; Lebedeva, N.N.; Panicheva, L.P. Alkylation of diols under phase transfer conditions: The influence of the nature of the substrate, alkylating agent, and organic solvent. Petroleum Chem. 2009, 49, 381-384. [CrossRef]

59. Saberian, M.; Naghash, H.J. Synthesis of allyl ether and benzyl methacrylate functionalized silane monomers for application in acrylate/montmorillonite nanocomposite emulsion. J. Adhes. Sci. Technol. 2020, 34, 153-166. [CrossRef]

60. Nichols, P.L.; Hamilton, R.M.; Smith, L.T.; Yanovsky, E. Allyl Ether of Starch. Ind. Eng. Chem. 1945, 37, 201-202. [CrossRef] 